\title{
O discípulo (Furtado) e o mestre (Prebisch), a inversão dos papéis*
}

The disciple (Furtado) and the master (Prebisch), the reversing of roles

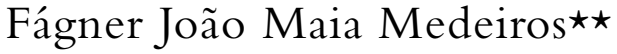

Resumo: A relação entre o discípulo Celso Furtado e o mestre Raúl Prebisch originou nos primórdios da escola da Cepal e modificou-se a cada decênio. Nesse artigo, analisamos a trajetória desses autores a partir de três distintos momentos que correspondem às décadas de 1950,1960 e 1970. Em cada um dos momentos, discutimos os diferentes encontros desses autores, associando-lhes às suas respectivas produções teóricas e à conjuntura latino-americana. Por resultado, no último decênio revelamos como a relação mestre-discípulo se inverteu, tornando o mestre Prebisch um leitor e seguidor das doutrinas do discípulo Furtado.

Palavras-chaves: Cepal. Celso Furtado (1920-2004). Raúl Prebisch (1901-1986).

\begin{abstract}
The relationship between disciple Celso Furtado and master Raúl Prebisch originated in the early days of the Eclac's school and has changed with each decade. In this article, we analyze the trajectory of these authors from three different moments that correspond to the 1950s, 1960s and 1970s. At each moment, we discuss the different meetings between these authors, associating them with their respective theoretical productions and the Latin American conjuncture. As a result, in the last decade we have revealed how the masterdisciple relationship has been reversed, turning the master Prebisch a reader and follower of the doctrines of the disciple Furtado.
\end{abstract}

Keywords: Eclac. Celso Furtado (1920-2004). Raúl Prebisch (1901-1986).

\footnotetext{
* Submissão: 23/12/3020 | Aprovação: 16/01/2021 | DOI: 10.29182/hehe.v24i1.786

$\star \star$ Doutorando em Economia pelo CEDEPLAR/UFMG | E-mail: fagnerjmaia@gmail.com | ORCID: 0000-0003-0366-8535
} 


\section{Introdução}

O objetivo deste artigo é acompanhar a trajetória intelectual de dois ícones do estruturalismo latino-americano que nada ficam a dever a seus pares estrangeiros: Raúl Prebisch e Celso Furtado. Furtado e Prebisch, ao longo de suas trajetórias, dedicaram-se exaustivamente ao estudo do subdesenvolvimento da América Latina, fazendo-os figurar como parte do núcleo formador de teorias originais e duradouras para o desenvolvimento periférico.Além de terem ocupado cargos de liderança em organismos regionais e no aparelho estatal brasileiro e argentino.

Nosso ponto de partida é a criação da Comissão Econômica para a América Latina e o Caribe (Cepal) em 1948, visto que esse foi o espaço inicial de encontro entre Prebisch e Furtado. Apesar de Furtado ter sido o primeiro a integrar a comissão, foi Prebisch (em 1949) que protagonizou e moldou o "rosto" da Cepal por meio de um conjunto de artigos seminais que ditaram os principais conceitos teóricos que iriam compor o arcabouço conceitual da comissão. Em vista disso, foi nos moldes do clima institucional da Cepal que se estabeleceu, inicialmente, essa relação "discípulo-mestre" entre Prebisch e Furtado. O discípulo, Furtado, desde seus primeiros textos já incorporou o vocabulário conceitual da Cepal, ${ }^{1}$ além de ter ajudado na difusão do trabalho do mestre (Prebisch), traduzindo seu texto inaugural para o português. Love (2001, p. 222) ainda lembra que "Prebisch e Furtado trabalharam em uníssono, com o fim de angariar o apoio do governo brasileiro para a Cepal".

Insistimos aqui que essa relação mestre-discípulo foi além de uma proximidade teórica, visto que também apareceu no contato institucional. Tanto por parte de Prebisch, Furtado era visto por ele como um jovem prodígio dentre os técnicos da Cepal (Dosman, 2011). Furtado, por sua vez, considerava Prebisch como um "grande heresiarca", afirmando ser o único economista latino-americano cujas ideias ultrapassavam o continente (Furtado, 2014). Não custa lembrar que Furtado não foi apenas um mero divulgador das ideias de Prebisch; ao longo da década de 1950, secundou as contribuições do autor contribuindo para construção do método histórico-estrutural e na formulação da teoria do subdesenvolvimento (Bielschowsky, 2004).

\footnotetext{
${ }^{1}$ Referimo-nos ao artigo "Características gerais da economia brasileira”, em que Furtado já mobilizava o conceito de deterioração dos termos de troca de Prebisch (Furtado, 1950).
} 
Após deixar a Cepal em 1958, as obras Formação econômica do Brasil, publicada em 1959, e Desenvolvimento e subdesenvolvimento, em 1961, marcaram a autonomia intelectual de Furtado. Todavia, o sentimento de discípulo permaneceu mesmo nos anos seguintes. A título de exemplo, no prefácio da obra O mito do desenvolvimento econômico, de 1974, Furtado (1985, p. 10) escreveu que "em plano distinto, mas não menos importante, é minha dívida para como Raúl Prebisch, cujas ideias sobre as relações centro-periferia constituem o ponto de partida de muitas das hipóteses aqui esboçadas". Em 1980, na obra Pequena introdução ao desenvolvimento, Furtado citou Prebisch como um dos autores que influenciaram a sua nova visão do fenômeno do desenvolvimento. Mesmo após a morte de Prebisch, nas obras Brasil: a construção interrompida, publicada 1992, e Em busca de novo modelo, de 2002, Furtado seguiu reconhecendo sua lealdade, dedicando um dos capítulos para Prebisch em cada um desses livros. ${ }^{2}$

No caso de Prebisch, o processo de amadurecimento intelectual do autor caminhou no sentido reverso no que tange à relação mestre-discípulo. Devemos esse apontamento a Barbosa (2012, p. 227), ao afirmar que "o mais interessante é que o mestre Prebisch se transforma em discípulo com $\mathrm{O}$ capitalismo periférico, publicado em 1981, mas escrito no final da década de 1970, quando não se encontra mais preso às artimanhas organizacionais e ao peso da ação política".

Em resumo, Prebisch, em sua última etapa intelectual, passou a mobilizar elementos da produção teórica de Furtado, a saber, o conceito de "dependência cultural" apareceu para retratar a dita "sociedade privilegiada de consumo". Além disso, a abordagem do excedente, muito antes praticada por Furtado, tornou-se nos anos setenta um fator chave para renovação multidisciplinar do pensamento de Prebisch. Uma evidência desse movimento está nos agradecimentos da obra derradeira de Prebisch ([1981] 1984, p. 9), em que redigiu o seguinte trecho:

[...] su colaboración conmigo ha sido inapreciable. Bien sabemos lo que significa su gran tarea intelectual: nadie ha penetrado con más profundidad en la interpretación del desarrollo. Siempre original e incisivo ha dado gran prestigio a su cátedra en la Sorbona. ¡Tiene el exilio político sus giros inesperados!

\footnotetext{
2 Em 1992, o terceiro capítulo do livro foi intitulado "Retorno à visão global de Prebisch". No livro de 2002, nos referimos ao sexto capítulo “O centenário de Raúl Prebisch” (Furtado, 1992, 2002).
} 
À luz dessa breve discussão, almejamos neste artigo adentrar na trajetória desses dois economistas que vez ou outra estiveram entrelaçadas seja pela atividade institucional ou pelas ideias sobre desenvolvimento. Para tal, dividimos esse artigo em três momentos da vida dos autores, no qual ilustram as seções desse artigo. Primeiro, embarcamos na década de 1950, retomando a época de constituição da Cepal. No entanto, destacamos as cisões entre os autores nesse período, que ao nosso ver elucidam suas divergências sobre os rumos do desenvolvimento da América Latina.

Em sequência, deslocamos para os anos de 1960, quando ambos os autores se reúnem no Instituto Latino-Americano de Planejamento Econômico e Social (Ilpes) com o intuito de revisar as teses da Cepal. Por fim, navegamos para o próximo decênio, no qual ambos os autores consolidam uma abordagem interdisciplinar para o estudo do desenvolvimento. Nossa linha mestra para cada um dos momentos está na relação mestre-discípulo e como essa relação se reconfigurou ao longo do tempo. Afora isso, expomos em poucas linhas as considerações finais.

\section{Naqueles velhos tempos na Cepal}

O elo entre o pensamento de Raúl Prebisch e Celso Furtado se deu na recém-criada Cepal. Conforme Love (2001), não faltavam semelhanças entre esses autores. Tal como Prebisch, Furtado era um economista que ao longo de sua carreira esteve associado a órgãos públicos de seu país, onde sempre atuou como "político não-partidário". Do mesmo modo, Furtado, assim como Prebisch, veio de uma região remota de seu país de origem, a "periferia da periferia". No entanto, Prebisch era de outra geração, quase vinte anos mais velho que Furtado, o que fez com que sua chegada na Cepal, em 1949, acompanhado por uma tríade de textos inaugurais ${ }^{3}$ da comissão, o tornasse um tipo de "maestro" para uma geração de jovens técnicos do organismo, entre eles, Furtado. Conforme Schatan (1986, p. 303), “pero este recuerdo del Maestro Prebisch dirigiendo y guiando a un grupo de jóvenes profesionales de distintas disciplinas - con la energía la agudez, el rigor teórico y el buen humor que le caracterizaban".

A contribuição teórica inicial de Prebisch foi recebida como um ver-

\footnotetext{
${ }^{3}$ Referimo-nos aos três textos inaugurais da Cepal que corroboraram na tarefa de tornar a comissão um órgão permanente em 1951: Prebisch (1950, [1949] 2011a, [1951] 2011c).
} 
dadeiro manifesto para a América Latina. ${ }^{4}$ Em linhas gerais, Prebisch contribuiu para formulação de uma Teoria do Desenvolvimento ao problematizar o comércio internacional, assim não se restringindo ao estudo do desenvolvimento da América Latina por meio de suas relações intrínsecas, mas dentro da chave de análise centro-periferia. Com efeito, a inserção dos países periféricos nesse sistema (centro-periferia) seria a origem e a finalidade da formação de uma estrutura econômica específica baseada na especialização produtiva de vocação primária-exportadora.

Dessa forma, a partir das teses consagradas de "deterioração dos termos de troca" " "tendência ao estrangulamento externo", Prebisch constatou que a reversão do subdesenvolvimento de uma nação deveria, impreterivelmente, ter como prelúdio a transformação da sua estrutura produtiva (industrialização), das suas formas de organização social e, por fim, o padrão de inserção internacional que o acompanha.

Diante disso, o sucesso inaugural da Cepal era claro. Hodara (2008, p. 53) chega a afirmar que Prebisch instituiu um tipo de "seita", no sentido weberiano, dentro da Cepal. Isto é, estabeleceu "una hermandad pequeña, solidaria, con una vigorosa consciencia de la Misión que debe desempeñar en el desarrollo regional". Derivado disso, Iglesias (2006) sublinha que não era exagero considerar a Cepal como o principal centro intelectual da América Latina no período, visto que a comissão passou a monopolizar todos os debates acerca dos problemas econômicos da região. Ademais, as ideias de Prebisch e de outros teóricos, como Furtado, tornaram-nos “conocidos mundialmente como “cepalinos”” (Magariños, 1991, p. 18). O próprio Furtado (1987, p. 377) reconheceu que "todo eso transformo a la institución em un caso sui generis en las Naciones Unidas".

Após o que Furtado (2014) chamou por "fase criativa" da Cepal (19491954), onde se buscou consolidar uma agenda de pesquisa, a próxima fase da comissão esteve voltada para oferta de cursos para formação técnica e elaboração de projetos para policy makers da região. Nesse período, Furtado passou a chefiar a Divisão de Desenvolvimento, posição que lhe conferiu o trabalho de elaborar estudos sobre as mazelas que entorpeciam o desenvolvimento dos países. Destacaremos adiante dois eventos emblemáticos que ajudam a entender divergências entre Furtado e Prebisch. Primeiro, a curta missão de

\footnotetext{
${ }^{4}$ Foi Albert Hirschman (1967) que cunhou por "manifesto latino-americano" o texto inaugural de Prebisch intitulado O desenvolvimento econômico da América Latina e alguns de seus principais problemas (Prebisch, [1949] 2011a), elaborado para Conferência de Havana em 1949.
} 
Prebisch na Argentina no logo imediato momento da queda de Juan Perón, em 1955. Em sequência, passamos ao estudo elaborado por Furtado sobre o México, concluído em 1957, sublinhando as polêmicas em torno desse documento que levaram a sua não publicação.

Dando início a exploração, com a queda de Perón, Prebisch logo foi cotado para assumir a direção econômica da Argentina, seu nome circulou pela imprensa. A relação de Prebisch com governo peronista era antiga, com a ascensão de Perón na década anterior, Prebisch precisou abandonar sua carreira no setor público argentino e exilar-se. Em 1955, Prebisch foi nomeado assessor econômico especial do presidente militar Eduardo Lonardi, com uma licença especial de três meses pela Organização das Nações Unidas (ONU), assim assegurando seu cargo na Cepal (DOSMAN, 2011).

Dentre suas funções, Prebisch preparou um estudo para um plano de recuperação econômica da Argentina, o Informe preliminar acerca de la situación económica (Prebisch, 1955). A base do diagnóstico de Prebisch foi acentuar a crítica ao peronismo, condenando a industrialização excessivamente fechada que gerou indústrias ineficientes, além da aguda inflação que rapidamente se alastrava pelo país. No que tange ao receituário, Prebisch tratou o período como entre as piores crises da Argentina, adotando um receituário à la FMI, com base em medidas restritivas para estabilização da economia atenuando a inflação. ${ }^{5}$ Nas palavras do autor, "achei que estava ruim, mas a realidade foi pior que a conjectura mais pessimista. [...] Só a austeridade e o sacrificio podem salvar a Argentina" (Dosman, 2011, p. 351).

Independentemente de Prebisch pedir o sacrificio de todas as classes sociais, em especial as mais ricas, e apontar a necessidade de reformas com base em critérios de justiça social, o anúncio do plano de Prebisch gerou tensões sociais e retomou velhos jargões do seu passado, vinculando-o à elite agrária e ao imperialismo inglês. ${ }^{6} \mathrm{O}$ plano foi interrompido poucos meses após sua aplicação, fazendo Prebisch retornar à Cepal; no entanto, esse evento revelou certos desentendimentos com outros membros da comissão, em especial, com Furtado. Fonseca e Salomão (2018) sustentam que entre Furtado e Prebisch haviam visões distintas sobre inflação e as feições do projeto de industrialização em curso, o qual denotaremos aqui.

\footnotetext{
${ }^{5}$ Ver Belini (2018).

${ }^{6}$ A crítica de Jauretche (1973), El Plan Prebisch: retorno al coloniaje, publicada no mesmo ano em resposta ao estudo de Prebisch explicita o caloroso debate que se instaurou na Argentina.
} 
Primeiramente, pouco antes da viagem de Prebisch para Argentina, a inflação já havia se tornado tema de debate para teóricos como Juan Noyola Vásquez, Furtado e outros notáveis membros da Cepal. Prebisch, em seus textos inaugurais, considerou a inflação como resultado do próprio processo de desenvolvimento dos países periféricos. Para o economista argentino, uma das causas da inflação seria o desequilíbrio crônico na balança de pagamentos, salientando que os desajustes no coeficiente de importação inevitavelmente causariam consequências monetárias, existindo ou não inflação (Prebisch, 1950).

Apesar de reconhecer essas conexões sobre o fenômeno monetário, Prebisch ainda atestava a eficácia de métodos tradicionais de combate à inflação devido ao apego em sua larga experiência no Banco Central argentino. As ressalvas de Prebisch sobre a inflação tornaram-se evidentes na curta passagem do autor pelo governo argentino, em 1955. Portanto, o receituário ortodoxo de Prebisch gerou atritos com seus discípulos da Cepal. O próprio Furtado (2014, p. 165) deixou claro suas divergências com Prebisch em sua autobiografia, ao dizer que "em todo caso, sua posição me parecia demasiado alinhada à ortodoxia local, dando excessiva ênfase ao problema da estabilidade, como se esta pudesse ser isolada para tratamento especial".

A partir da pista inicial fornecida por Prebisch e da "querela monetaristas versus estruturalistas" (Furtado, 2014, p. 165) dentro da Cepal, outros estudos foram realizados sobre o tema por outros cepalinos, como por Furtado, Noyola e Osvaldo Sunkel. ${ }^{7}$ Boianovsky (2012) presume que a saída de Prebisch tenha ajudado a impulsionar o debate inflacionário na instituição. Em suma, Bielschowsky (2004, p. 21) sintetiza o argumento desses estruturalistas, alegando que, para estes, a moeda várias vezes expandia-se passivamente, como resposta a autoridades monetárias e elevação de preços de origem estrutural - como inelasticidade da oferta de certos produtos. Desse modo, diferente das recomendações das doutrinas ortodoxas para os países periféricos, "a única maneira de evitar inflação seria alterando as condições estruturais que a provocam, e isto deve ser feito por meio de um esforço de crescimento econômico contínuo e planejado".

Especificamente sobre Furtado, Dosman (2011, p. 368) afirma que o autor, junto a Noyola, diagnosticou a inflação como um sintoma do atraso institucional e político, exigindo soluções mais complexas. Além disso, Fon-

\footnotetext{
${ }^{7}$ Listamos alguns dos estudos que foram publicados sobre o tema: (Furtado, 1954; Sunkel, 1958;Vásquez, 1957).
} 
seca e Salomão (2018) mostram que Furtado reprovava o argumento (utilizado por Prebisch na Argentina) de que o "custo salarial" era um componente que gerava pressão inflacionária.

Para além do debate inflacionário, Prebisch e Furtado também divergiram sobre o curso da industrialização por substituição de importações (ISI). Embora Prebisch, a datar pelo manifesto de 1949, tenha defendido a necessidade de se voltar hacia adentro e promover a industrialização, com passar dos anos, o autor chamou a atenção para a necessidade de exportar manufaturas. Mesmo nos primeiros textos, Prebisch destacou os limites do processo de industrialização, vide o estreito mercado interno dos países. A partir da publicação La cooperación internacional en la política de desarrollo latinoamericano (Prebisch, [1954] 1982), Prebisch direcionou-se para a ideia de que a exportação industrial seria uma medida crucial para escapar do estrangulamento externo e, com efeito, facilitar o desenvolvimento industrial pela redução dos custos de produção. Em suma, "sin embargo, la verdad es bastante distinta. Prebisch se dio cuenta de que el proceso de la ISI era como exprimir un limón: la primera vez salía mucho jugo pero en los intentos posteriores se obtenía cada vez menos" (Toye; Toye, 2006, p. 27). Nessa mesma linha, selecionamos um trecho de uma entrevista concedida em 1971 por Prebisch que ilustra essa questão:

[...] decir que teníamos un modelo de "sustitución de importaciones" cuando fuimos los primeros en hablar de comercio recíproco entre los países latinoamericanos y de la exportación de manufacturas al resto del mundo es torcer, desfigurar nuestro pensamiento de esa época. (Magariños, 1991, p. 149-150)

Diferente de Prebisch, que enfatizava a inserção externa como um componente para impulsionar o processo substitutivo, Furtado destoava quase por completo dessa estratégia, preconizando o mercado interno ao lado de medidas de distribuição de renda em seus estudos. Isso poderia ser verificado no relatório El desequilibrio externo en el desarrollo económico latinoamericano: el caso de México (Cepal, 1957) dirigido por Furtado, por dois anos, ao lado de outros membros da Cepal, como os mexicanos Noyola e Óscar Soberón e o chileno Sunkel. O objetivo desse relatório foi diagnosticar as causas e tendências do desequilíbrio externo mexicano para, então, propor medidas para enfrentá-lo.

Nesse relatório, Furtado apontou que a ISI no México, embora dinâmica, estava atrelada ao aumento da desigualdade. O caso mexicano se diferenciava pelo setor externo dinâmico devido à proximidade da economia 
norte-americana. Conforme os argumentos de Furtado, eram necessárias políticas regulatórias, tal como controle de câmbio ao invés de desvalorizações periódicas que premiava a especulação e impulsionava a concentração de renda no país (Furtado, 2014). Dosman (2011, p. 378) afirma que era um relatório inovador que "desbravava um novo terreno para expandir o pensamento e o trabalho da Cepal, a fim de compreender a fase mais complexa do desenvolvimento que a região experimentava agora".

No entanto, o relatório não agradou o governo do México. Foi pedido que ele fosse invalidado e a Cepal outorgou essa decisão através de Prebisch, medida que gerou um novo atrito entre os autores. Somado a isso, advertido pela ONU anos antes pela publicação de A economia brasileira (Furtado, 1954), Furtado agora teria seu estudo sobre o México não publicado. Esse episódio o deixou insatisfeito com o serviço internacional, chegando a escrever em seu diário em dezembro de 1954:

Muitas vezes me perguntei se poderia me transformar plenamente num funcionário internacional. Não sem alguma surpresa sinto ter feito um progresso significativo nesse sentido. Pesa-me, por isso, ver-me na contingência de ter que reconsiderar meus planos futuros, nesse momento em que se coloca para mim a dúvida de saber se poderei conservar e exercer o direito de publicar de vez em quando algum estudo, no campo da teoria econômica, sob minha responsabilidade pessoal. Se chego a perceber que não existe um interesse real por parte de meus superiores para que eu possa exercer esse direito, eu teria que renunciar ao prazer e ao privilégio que é trabalhar na Cepal. (Furtado, 2019, p. 128)

Na mesma direção, em sua autobiografia, Furtado (2014, p. 171) acrescentou que na Cepal "a liberdade de pensamento era tolerada se os problemas abordados eram abstratos: relação de trocas, excedente estrutural de mão de obra, tendência ao desequilíbrio externo e coisas tais". E quanto ao desarranjo com Prebisch, reunimos duas declarações de Furtado, sendo a primeira um trecho de uma entrevista concedida em 2001.

Quando escrevi esse livro [A economia brasileira], Prebisch não gostou, não aprovou. [...] Porque ele achava - mandou-me dizer indiretamente - que os técnicos da Cepal deviam todos pensar pela instituição. $\mathrm{O}$ que escrevessem era para a instituição, o que me pareceu um absurdo. Mas era o temperamento dele. (Vieira, 2004, p. 34) 
Encontramos o segundo relato numa carta do brasileiro ao cepalino Regino Boti.

Estou por aqui lendo algo tranquilamente e descansando um pouco o espírito. Meu último ano de Cepal não foi nada fácil. Enfrentei crescentes dificuldades para entender-me com o maestro. Esse trabalho tão inocente sobre o México foi arrancado a fórceps depois de dias e dias de extenuantes discussões. (Furtado, n. d. apud Fonseca, Salomão, 2018, p. 76)

O resultado desses atritos foi o pedido de licença de Furtado em 1957, quando o brasileiro optou por dedicar-se, por um curto período, à carreira acadêmica. A partir de setembro, Furtado passou uma temporada no King's College da Universidade de Cambridge, supervisionado por Nicholas Kaldor, momento em que escreveu sua obra Formação econômica do Brasil. Em meados de 1958, Furtado retornou ao Brasil e deu início ao processo de afastamento da Cepal, concretizado no mês de outubro. Dosman (2011, p. 377-378) afirma que a equipe ficou comovida, visto que Furtado era tido como o substituto natural de Prebisch para liderança da Cepal. ${ }^{8}$

Fonseca e Salomão insistem que essas desavenças entre Prebisch e Furtado resultavam de suas diferentes propostas de "estilos de desenvolvimento". Entretanto, levantaremos aqui outras respostas para esse atrito entre mestre e discípulo. Primeiramente, é preciso resgatar o caráter da Cepal como órgão regional da ONU criado no contexto da Guerra Fria. Nesse sentido, a comissão foi resultado de uma concessão da época, devendo seguir à risca o "regimento estadunidense", sob pena de retaliações ou perda de grau de autonomia.

No caso da figura de Prebisch, sua escolha para presidir a Cepal - avaliada pelos Estados Unidos - não levou em consideração o caráter identitário e de afirmação da América Latina. Ao contrário, Souza (2015) especula que sua escolha tenha sido em função da oposição de Prebisch ao Perón, isto é, baseada no progressismo limitado do autor. Dentro da rotina do organismo, Prebisch era cauteloso na direção da Cepal, sabia que precisaria lidar com chefes de governos em busca de consensos em vez de conflitos, como lembrou Hodara (1987), estes eram seus clientes. ${ }^{9}$ Dentro da comissão, Prebisch "re-

\footnotetext{
${ }^{8}$ Em entrevista, Furtado revelou que foi procurado por Prebisch quando retornou de Cambridge. "Quando voltei, disse a Prebisch que só me interessaria uma missão no Brasil. Ele [Prebisch] queria que eu fosse para Santiago" (Vieira, 2004, p. 34).

${ }^{9}$ Um claro exemplo dessa postura está na introdução de D’Aguiar (2008) para Ensaios sobre a Venezuela,
} 
visava pessoalmente todos os relatórios antes da publicação aconselhara Furtado a não ser impetuoso e era escrupuloso ao tentar ser objetivo e neutro com governos, a ponto de se opor a recomendações gerais no relatório da Cepal" (Dosman, 2011, p. 333).

A cautela do autor se estendia inclusive no ato de escrita, o que Gunnar Myrdal denominou "diplomacia del linguaje", sendo uma escrita formal que respeita os imperativos burocráticos das organizações (Hodara, 2008). Ainda sobre o tema, Bianchi (2003) mostra como até o vocabulário de Prebisch alterava-se conforme seu público. Nesse sentido, na qualidade de secretário-executivo de organismos regionais isso sempre implicou o maior grau de neutralidade dos seus relatórios. Nas palavras do próprio Prebisch, "eu não podia apresentar um relatório aos governos pregando a necessidade de implementar medidas internas drásticas porque eles responderiam drasticamente, pedindo minha cabeça em vez de aceitar minhas ideias" (Dosman, 2011, p. 540).

Isso posto, os diferentes relatos apresentados ilustram diferenças vitais entre Prebisch e Furtado. Prebisch era um líder pragmático plenamente entregue ao serviço internacional. Era também um diplomata que atuava entre a "cruz e a espada", para que eventuais conflitos não deduzissem um apelo maior ao intervencionismo sobre a Cepal. Enquanto isso, Furtado era mais ambicioso e desejava avançar em seus estudos teóricos. Além disso, ocupou a "divisão vermelha" do organismo (Dosman, 2011, p. 305), quer dizer, a ala mais radical. Em entrevista, o próprio Furtado enumerou suas dissemelhanças com Prebisch.

Prebisch não captava o fenômeno histórico. Ele era mais um técnico. Via a Economia como economista. Em segundo lugar, ele não via a dimensão social com a mesma urgência que eu. Ele vinha de um país, a Argentina, onde havia muito crescimento social. O povo vivia bem. Os operários comiam churrasco, na rua, em Buenos Aires... E eu vinha do Brasil, do Nordeste. Tinha uma percepção da pobreza, tinha urgência! Havia diferenças, mas isso não impedia que colaborássemos. Eu era um grande admirador de Prebisch, devo muito a ele. A Cepal foi um momento importante. (Vieira, 2004, p. 34)

de Furtado. Nesse texto, é evidente o cuidado de Prebisch na liderança da Cepal ao lidar com o governo militar de Jiménez, em 1957. Esse foi outro estudo de Furtado que não foi publicado. 
Por esse ângulo, os atritos entre mestre e discípulo estavam circunscritos por seus distintos propósitos dentro da dinâmica institucional da Cepal.

\section{Tempos de revisão e de esperança por reformas}

Se na década de 1950 houve uma certa cisão entre Prebisch e Furtado, no decênio seguinte o cenário era distinto. Furtado (2014, p. 167) escreveu em sua autobiografia que as ideias de Prebisch sobre inflação estavam evoluindo, "quando o fantasma argentino já não o perseguia". Furtado se referiu à publicação de O falso dilema entre desenvolvimento econômico e estabilidade monetária (Prebisch, [1961] 2011b). Nesse documento, Prebisch defendeu com veemência que não havia um dilema entre realizar políticas de desenvolvimento econômico e manter a estabilidade monetária, pois a busca pelo desenvolvimento via transformações estruturais seria a única via para atacar de vez a inflação no longo prazo.

A novidade sobre a inflação no pensamento de Prebisch estava em reconhecer o efeito de tensões sociais sobre o processo inflacionário. Sendo assim, Prebisch aproximou-se dos estudos de Furtado, Noyola e outros, ao mostrar que a inflação era por vezes utilizada como instrumento redistributivo pelas classes de altas rendas em detrimento da massa populacional sem mecanismos de defesa. Outro caso era designado ao regime imperante de posse de terra que se opunha ao fornecimento regular de alimentos que acompanhasse o crescimento populacional do período.

A autobiografia do Furtado também nos revela que os autores mantinham certo contato. Furtado (2014, p. 359) escreveu que: "Prebisch acompanhava o trabalho que eu realizava no Brasil como se se tratasse de uma prolongação daquelas lutas em que havíamos empenhado juntos pelas plagas latino-americanas". Outro encontro dos autores foi no décimo período de sessões da Cepal em Mar del Plata, em 1963, sendo a despedida de Prebisch da Cepal. Furtado (2014, p. 360), como representante do Brasil, realizou o discurso de encerramento mencionando sua relação mestre-discípulo com Prebisch.

Quando afirmei que encerramos um ciclo na vida da Cepal, indiquei que esse fato não se deve propriamente ao afastamento da secretaria executiva do dr. Raúl Prebisch. Isso porque a influência do pensamento desse grande mestre da América Latina, que somente agora se exerce em sua plenitude, continuará presente 
como força orientadora de todos nós. Para os homens que se projetam pelo pensamento criador e têm a faculdade de influir sobre os acontecimentos pela força de suas ideias, não existe despedidas, porque eles sempre estarão presentes.

Como dito, nossa segunda parada contempla o encontro de Prebisch e Furtado no Ilpes, em 1964. Antes disso, Furtado, de volta ao Brasil, ocupou-se como superintendente da recém-criada Superintendência do Desenvolvimento do Nordeste (Sudene), em 1959. Em seguida foi o primeiro ministro do Planejamento, em 1963, quando preparou um plano de estabilização que conciliava ajuste recessivo com reformas estruturais, o Plano Trienal. Essa trajetória foi interrompida com o golpe militar de 1964, que, por meio do Ato Institucional $\mathrm{n}^{\circ} 1$, obrigou Furtado a se exilar. Prebisch, por seu turno, esteve envolvido com a criação da Associação Latino-Americana de Livre-Comércio (Alalc). No decênio seguinte incorporou o quadro da Aliança para o Progresso, em 1961, e trabalhou na criação do Ilpes, em 1962; e, por fim, partiu para novos horizontes, assumindo o posto de diretor-geral da United Nations Conference on Trade and Development (Unctad), onde, segundo Dosman (2011), difundiu o "evangelho da Cepal” para o Terceiro Mundo.

Destarte, Martín (2016) afirma que a cidade de Santiago havia se tornado o principal ponto de refúgio para intelectuais após a ditadura instaurada no Brasil. Furtado (2014, p. 404) logo se instalou no Ilpes, "onde eu trabalhava na preparação de um seminário sobre os primórdios dessa instituição”, bem como interpretava os problemas recentes que assolavam a América Latina. É pertinente ressaltar que era um período de recessão marcado pelo esgotamento da ISI. Entre 1960 e 1964, a América Latina cresceu somente 0,4\% ao ano. Ademais, o contexto geopolítico agravou-se desde a Crise dos Mísseis no ano de 1962 (Bielschowsky, 2018; Rodríguez, 2009).

O seminário teve início em junho; Furtado (2014, p. 410) afirmou que "coube-me fazer a apresentação desses textos [da Cepal] como introdução ao debate". Prebisch, por sua vez, chegaria mais tarde, após o encerramento da Unctad I em Genebra. Mallorquín (1999) sublinha que esse seminário atraiu renomados sociólogos e economistas interessados em refletir sobre o subdesenvolvimento da América Latina. A saber, alguns desses eram Osvaldo Sunkel, PedroVuscovic, Francisco Weffort, Fernando Henrique Cardoso, Enzo Faletto, Ricardo Cibotti, José Medina Echavarría, Benjamin Hopenhayn e Noberto González. Furtado (2014, p. 410) esclareceu que "estava longe de ser um seminário acadêmico, pois ninguém fazia jogo pessoal", era a primeira 
vez que um grupo de intelectuais se reuniu para discutir os impasses da América Latina a partir de textos teóricos elaborados na própria região, "compaginando-os com a experiência vivida da qual muitos de nós tínhamos conhecimento direto".

De modo geral, o pano de fundo do debate era reconhecer que as progressivas transformações no sistema produtivo não foram capazes de garantir o crescimento autossustentado, muito menos atendeu a critérios de justiça social. A partir de algumas provocações impostas por Furtado, rodaram a mesa temas como: imperialismo, dependência tecnológica, divisão internacional do trabalho e os aspectos políticos do desenvolvimento. Derivado disso, destacaram-se os sociólogos Medina e Cardoso na intenção de ampliar o horizonte do debate na direção da esfera social e política (Furtado, 2014). Quanto a Prebisch, Bianconi (2016) relata que a participação do autor foi em dois sentidos. Primeiro, expondo suas reflexões sobre bloqueio estrutural presente no desenvolvimento da América Latina. Segundo, divulgando a relevância da Unctad para alcançar uma Nova Ordem Econômica Internacional (Noei).

Furtado (2014, p. 412) afirma que o "objeto principal do seminário" era a temática da estagnação, que veio a dominar o pensamento latino-americano. Esse debate era reflexo de um conjunto de teses previamente elaboradas pelos autores. A princípio, Prebisch publicou, em 1963, Dinâmica do desenvolvimento latino-americano (Prebisch, 1968), em que assinalou à América Latina uma crise de insuficiência dinâmica, quer dizer, a própria estrutura econômica da região era incapaz de absorver a totalidade da mão de obra disponível. Conforme Prebisch, a razão disso estava na estrutura social concentrada que entorpecia o desenvolvimento mediante a concentração dos frutos da produtividade em uma pequena camada populacional, ao lado da estrutura anacrônica da terra que impulsionava um processo de urbanização desenfreado. Tudo isso foi agravado pela composição da técnica moderna, sendo inapropriada para o estágio de desenvolvimento da América Latina.

No caso de Furtado, Bielschowsky (2011) sublinha que seu diagnóstico era menos efêmero. Furtado deu continuidade às teses de Prebisch sinalizando uma tendência inexorável à estagnação. Mediante o exposto, os marcos iniciais dessa tese estavam na obra Dialética do desenvolvimento (Furtado, 1964), em 1964, e elaborada com maior veemência, dois anos depois, em Subdesenvolvimento e estagnação na América Latina (Furtado, 1966). O cerne do argumento de Furtado estava na queda da relação produto-capital à medida que a industrialização avançava para estágios mais complexos em setores intensivos em capital. 
Furtado mostrou como a concentração de renda estava desenhando uma estrutura produtiva voltada para atender uma pequena elite, e a cada novo ciclo menos capital era direcionado para participação dos salários na renda, com efeito debilitando a estrutura da demanda e reforçando a desigualdade como traço vital de uma estrutura condenada à estagnação.

Em linhas gerais, Furtado, assim como Prebisch, construiu uma linha argumentativa pela negativa, isto é, defendia que faltaram condições institucionais e sociais que permitissem que as condições econômicas fossem traduzidas em desenvolvimento. Para tal, Furtado e Prebisch ratificaram um receituário reformista para a crise, reivindicando que fosse realizado um conjunto de reformas estruturais, tais como: reforma financeira, política, tributária, e a reforma agrária como carro-chefe.

É pertinente ressaltar que essas teses constituíram os argumentos econômicos basilares em favor das ditas "reformas de base" que foram implementadas na América Latina. Embora o diagnóstico seja similar, Bielschowsky (2018) afirma que Furtado e Prebisch chegaram às reformas por vias distintas. Enquanto a ênfase de Furtado residiu sobre a ampliação do mercado interno, Prebisch, por sua vez, destacou o efeito das reformas para viabilização do investimento produtivo para absorção de mão de obra. ${ }^{10}$

De volta ao seminário, os relatos de Furtado jogam luz sobre suas diferenças com o mestre. No Ilpes, Prebisch descreveu que a ascensão do autoritarismo era induzida pela formação de conjuntos industriais progressivamente mais fechados, somada ao acúmulo de tensões sociais que conduziria, impreterivelmente, à disseminação desses Estados autoritários. Diante disso, era patente a visão esperançosa de Prebisch com a "boa diplomacia" ao contar que a estagnação seria superada modificando a estrutura de poder do comércio internacional, ou seja, por resultado de concessões obtidas pela Unctad. Da mesma forma, Prebisch mantinha uma visão ilustrada sobre o Estado, contando como dada a possibilidade de este executar uma ampla agenda de reformas sociais.

Furtado (2014,p. 414), conduzido pelo clima desesperançoso no Brasil, julgou as saídas de Prebisch simplistas e ingênuas. "Parecia-me que era uma visão idealista do papel que podia desempenhar o Estado nas condições do subdesenvolvimento. Reduzir o consumo dos grupos de altas rendas, dizia

\footnotetext{
${ }^{10} \mathrm{O}$ balanço e a síntese das divergências entre Furtado e Prebisch nesses anos pode ser conferido em Medeiros e Cosentino (2020).
} 
eu, constitui por si só uma autêntica revolução”. Essa postura cética presente no pensamento de Furtado antecipava certos traços contidos nas suas publicações seguintes. Para Mallorquín (1999), tratava-se de mudanças teóricas no olhar do autor sobre a dinâmica do capitalismo mundial e seus efeitos sobre a periferia.

Como dito anteriormente, o mestre e o discípulo estiveram lado a lado no Ilpes debatendo os impasses do quadro teórico clássico da Cepal. Nesse período, ambos os autores compartilharam uma agenda de pesquisa muito similar orientada por reformas; todavia, seguiram rumos distintos quando as intervenções no Ilpes iniciaram. Dosman (2011) sublinha que o instituto, paulatinamente, perdia sua autonomia e fontes de recurso à medida que os governos militares da região foram perdendo interesse pelas pesquisas ofertadas. A título de exemplo, pesquisas relevantes em curso foram vetadas, o que incluiu o estudo pioneiro iniciado por Furtado e Cardoso sobre as empresas multinacionais.

Com efeito, Furtado abandonou o Ilpes poucos meses após o seminário, voltando-se exclusivamente à carreira acadêmica; primeiro, nos Estados Unidos, Universidade Yale, e depois na França, onde se fixou na Universidade de Paris. Foram os anos mais fecundos de sua produção teórica, contabilizando dez novos livros no período. Diferente de Furtado, Prebisch seguiu sua rotina dentro dos organismos, mantendo-se na Unctad até 1969, em seguida retornando ao Ilpes e prestando serviços à ONU.

\section{Uma aventura multidisciplinar}

Nesta seção, deslocamos para nossa última parada nos anos setenta, quando as taxas de crescimento da América Latina voltaram a subir vertiginosamente e mostraram-se capazes de conciliar crescimento com desigualdade social. A marca central desse período talvez tenha sido a contenção das reformas de base por governos autoritários que se alastraram pelo Cone Sul. Além do mais, era um período de transição; o fim do Bretton Woods foi um marco para o reordenamento das forças internacionais, marcado pelo aumento dos fluxos financeiros e pela crescente circulação de empresas transnacionais (ETNs). Perante esse quadro, tanto Furtado quanto Prebisch procuraram brindar novas interpretações no sentido da interdisciplinaridade. De acordo com Love (2001, p. 221), 
[...] é difícil separar algumas das contribuições iniciais de Furtado das de Prebisch e, na década de 1970, os pontos de vistas de ambos voltaram a convergir, dessa vez para enfocar os padrões de consumo das camadas superiores da sociedade latino-americana como sendo a força motora das economias daquela região, vistas como não-acumuladoras e dependentes.

Logo em 1974, Furtado impactou as discussões sobre desenvolvimento a partir da publicação do livro O mito do desenvolvimento econômico (Furtado, 1985), sendo resultado de um amplo movimento de revisão crítica do autor. O ponto de partida de Furtado foi mostrar que o desenvolvimento - homogeneizador e autônomo - almejado pelos países periféricos era na verdade um mito. Furtado tirou essa conclusão influenciado pelos resultados expressos no relatório do Clube de Roma, insistindo na impossibilidade de homogeneização dos padrões de consumo em níveis mundiais. Para Furtado, essa era uma ilusão fabricada pelas próprias teorias do desenvolvimento. No mesmo ano, encontramos em seu diário um trecho no mesmo sentido. "Todos os mitos em que acreditei! Existirá algo fora dos mitos, em que se possa acreditar?" (Furtado, 2019, p. 233).

A par disso, Furtado examinou outras formas de captar a natureza do subdesenvolvimento, o que mais tarde chamaria por "visão global de estruturas sociais historicamente identificadas" (Furtado, 1977, p. 11). Segundo o autor, era preciso focalizar tanto no processo de produção, local onde o excedente era formado e apropriado, quanto na esfera da circulação, no qual o uso do excedente estabelecia vínculos diretos com padrões de consumo copiados dos países desenvolvidos. Em suma, essa dupla articulação engendrava a "dependência cultural", sendo a base do processo de reprodução das estruturas sociais periféricas.

Dessa maneira, a dimensão cultural recebeu lugar de destaque na interpretação de Furtado. Nesses termos, o uso do excedente na América Latina teria conduzido a algo muito distinto do desenvolvimento, o que Furtado (1985, p. 81) chamou por "modernização", quer dizer, "esse processo de adoção de padrões de consumo sofisticados (privados e públicos) sem o correspondente processo de acumulação de capital e progresso nos métodos produtivos".

Em vista disso, Furtado esclareceu que desde o último quartel do século XIX foi transplantado à América Latina padrões de consumo da dita "civilização industrial", sem em troca entregar um sistema produtivo adequa- 
do, assim restringindo-a à vocação primário-exportadora. Por consequência, a dependência cultural condicionou uma formação social subdesenvolvida. Nos anos setenta, Furtado sublinhou que o subdesenvolvimento da região foi remodelado. Em outros termos, a industrialização se constituiu para atender o mimetismo cultural de uma ínfima parcela social que exercia domínio sobre o excedente. Aqui reside a explicação de Furtado: a industrialização somente alterou as feições do subdesenvolvimento, a dependência que antes imitava o padrão de consumo externo, agora havia se enraizado no sistema produtivo e assumido a forma de subsidiárias de grandes empresas que transmitem o modo de vida da civilização industrial. Somado a isso, o avanço das ETNs era sucedido pela perda da autonomia dos Estados nacionais quanto às decisões do desenvolvimento, sobretudo sobre o processo de criação tecnológico que continuaria restrito ao centro (Furtado, 1985).

Nos anos que seguem, Furtado aprofundou sua análise no sentido da interdisciplinaridade. Na obra Prefácio a Nova Economia Política (Furtado, 1977), em 1976, Furtado ratificou o conceito de excedente como componente central para uma análise global da acumulação e de suas relações com as estruturas de dominação. Bianconi e Coutinho (2020) mostram como esse conceito tornou-se um componente que permitia a integração entre os aspectos econômicos, políticos e culturais do pensamento de Furtado. Finalmente, ressaltamos o livro Pequena introdução ao desenvolvimento (Furtado, 1980) como um produto acabado desse processo.

Nessa obra Furtado se propôs a contribuir para a criação de uma linguagem comum aos distintos ramos das ciências sociais, e na elaboração de um quadro social que permitisse apreender a realidade em suas múltiplas dimensões. Em linhas gerais, Furtado defendeu que a ideia de desenvolvimento estaria associada a três dimensões: (1) o incremento da eficácia social da produção; (2) da satisfação das necessidades elementares da população; e (3) da consecução de objetivos almejados por grupos dominantes. Isso posto, a matéria do desenvolvimento, para Furtado, deveria necessariamente envolver o estudo de uma teoria da acumulação, da estratificação social e de uma teoria do poder, no sentido de constituir um ponto de convergência entre as distintas ciências sociais e, por consequência, apreender o desenvolvimento como um processo global.

Análogo a Furtado, Prebisch (1983, p. 1087), anos mais tarde, passou por um momento de revisão crítica, que chamou de "quinta etapa, probablemente la última, de mi pensamiento sobre los problemas del desarrollo 
económico". ${ }^{11}$ Tal fase teve início em 1976, momento em que Prebisch finalmente abandonou suas tarefas institucionais e passou a dedicar-se integralmente à publicação acadêmica como diretor da Revista de la Cepal, criada no mesmo ano. De acordo com Prebisch (1983, p. 1087), foi "un periodo final en que él, libre de responsabilidades ejecutivas por primera vez en muchos años, he podido revisar y desarrollar sistemáticamente mi pensamiento".

A partir do ano de 1976, Prebisch lançou um conjunto de profícuos $\operatorname{artigos}^{12}$ que, mais tarde, foram incorporados na obra de síntese Capitalismo periférico, crisis y transformación (Prebisch, [1981] 1984). Do mesmo modo que Furtado, Prebisch (1978, p. 167) afirmou ter navegado sobre os mitos do desenvolvimento, agora seria preciso abandonar essa visão de que a periferia poderia "desarrollarse a imagen y semejanza de los centros". Em entrevista no ano de 1978, Prebisch reforçou sua afirmação, ao dizer que "we thought that an acceleration of the rate of growth would solve all problem. Now we know that does not happen" (Gauhar; Prebisch, 1980, p. 18).

Para escapar dessas crenças, Prebisch também se dirigiu para uma interpretação multidisciplinar que fosse capaz de captar a natureza multifacetada do desenvolvimento. $\mathrm{O}$ que o próprio Prebisch denominou por "análise global do desenvolvimento"; sendo global, de um lado, pela necessidade de incorporar o capitalismo periférico como parte integrante do fenômeno geral do capitalismo; de outro, por sobrepor uma análise econômica, subordinando-a a outras esferas de conhecimento (social, política, ambiental e cultural) (Prebisch, 1976).

Dando início à exploração, Prebisch conceituou o "capitalismo periférico" como um processo dinâmico de irradiação de técnicas, ideias, instituições e ideologias da hegemonia secular do centro para uma estrutura fundamentalmente distinta. Nesse sentido, Prebisch sublinhou que o capitalismo, em seu livre curso, sustentava uma dinâmica centrípeta, no qual a acumulação de capital e o progresso técnico se concentravam no centro. Portanto, o esquema centro-periferia, compartilhava a existência de capitalismo inovador (centro), ao lado de um capitalismo imitativo (periferia) que arcava com os custos do seu atraso histórico (Prebisch, 1978).

Em face dessas questões, Prebisch tornou-se mais cético quanto à possi-

\footnotetext{
${ }^{11}$ Referimo-nos ao único ensaio biográfico de Prebisch, intitulado Cinco etapas de mi pensamiento sobre el desarrollo.

${ }^{12}$ Referimo-nos à trilogia do capitalismo periférico de Prebisch, publicada respectivamente em 1976, 1978 e 1980.Ver Prebisch (1976, 1978, [1980] 2008).
} 
bilidade de romper com a inércia do subdesenvolvimento, reconhecendo a desigualdade social e o desemprego estrutural como características inerentes à estrutura do capitalismo latino-americano, e que tais traços floresciam em desajustes sociais e políticos. Prebisch, ao contrário de seu receituário anterior, passou a alegar que as reformas estruturais praticadas dentro do sistema prevalecente apenas conduziram a América Latina para um ciclo em que os ganhos adquiridos pelas camadas inferiores resultaram em pressões sobre a produção do excedente; que, até então, atuava em favor do consumo privilegiado das camadas elevadas. Por consequência, a redução do excedente terminaria sempre engendrando em uma nova crise econômica e política que se alastraria até que novamente fosse restabelecido o uso do excedente para fins não produtivos, a serviço do que o autor chamou de "sociedade privilegiada de consumo".

Diante desse diagnóstico, Prebisch elaborou como saída uma "teoria da transformação", com isso talvez superando o radicalismo de Furtado. De forma geral, essa transformação consistia em romper com os princípios que assentam o capitalismo periférico, na busca por outro tipo de sistema de organização social. A proposta do autor corresponde a uma síntese entre o liberalismo e o socialismo. O primeiro indicava a adoção de características coletivas no que tange à correção das disparidades estruturais da renda, visando obter o "uso social do excedente". Em alternativa, o individualismo estaria presente na garantia das liberdades políticas e econômicas dos indivíduos. Por resultado, todas as decisões deveriam ser orientadas pelo planejamento democrático (Prebisch, 1984).

Afinal, a novidade no esquema de Prebisch estava no seu novo arsenal teórico. O autor adotou categorias de estratificação social em sua análise (estratos inferiores, intermediários e superiores), tendo cada um desses estratos um certo grau de poder, seja ele sindical, político, social ou econômico. Em vista disso, o conflito distributivo pelo excedente estava no âmago da análise global implementada por Prebisch. Em outros termos, o excedente estava no centro da crise do capitalismo periférico, e o estudo da formação e apropriação deste era a única ferramenta apta para incorporar as estruturas internas de poder, bem como suas relações com o centro hegemônico, quer dizer, a dependência. Com base nessa análise, o olhar de Prebisch para a estrutura social denotava a existência de uma "sociedade de consumo" enraizada no sistema político local e internacional que sempre estava disposta a mobilizar seu poder para assegurar o mesmo perfil de demanda dos centros industriais.

A argumentação aqui exposta não deixa dúvidas sobre a proximidade 
entre mestre e discípulo nessa fase. Derivado disso, a teorização de Prebisch acerca da dimensão cultural, em especial, sobre a "sociedade de consumo", convergia para os mesmos moldes da "civilização industrial" delineada por Furtado.Além do mais, a abordagem do excedente incorporada por Prebisch muito antes já fazia parte do núcleo teórico de Furtado. Bianconi e Coutinho (2019, p. 1150) chegam a sugerir que o "uso social do excedente" de Prebisch revelava certa proximidade entre os autores, uma vez que ambos consideravam "que no tratamento dos problemas do desenvolvimento econômico não é possível desconectar os fatores econômicos das estruturas sociais, também Prebisch destacaria a necessidade de se alargar o campo de visão para além da teoria econômica".

Por fim, também havia a questão da dependência. Prebisch, assim como Furtado, incorporou esse conceito em suas formulações nos anos setenta. Conforme indica Di Filippo (2019, p. 221), alguns teóricos do estruturalismo, como Furtado, Sunkel e Prebisch, "began to use the language of dependency but without fully subscribing to what was called dependency theory".

Diante dessas evidências, devido ao fato de Furtado muito cedo ter conseguido se afastar de análises restritas ao fenômeno econômico, isso o tornou, nos anos setenta, uma referência sui generis para compreensão da natureza do subdesenvolvimento. Desse modo, aos 75 anos, o mestre (Prebisch) tornou-se um leitor do seu discípulo (Furtado) e em certos momentos de sua obra utilizou inclusive os mesmos termos de seu discípulo, seja para referir-se ao "mito do desenvolvimento", seja para tratar da "dependência cultural”. De todo modo, tanto Furtado como Prebisch, no fim da vida, asseguraram uma visão que o desenvolvimento deveria ser, impreterivelmente, democrático, homogeneizador e autônomo.

Antes de encerrar, voltamos rapidamente à relação dos autores. Algumas pistas foram encontradas nas publicações de Furtado. Sobre a publicação final de Prebisch, Furtado (2011, p. 444) comentou que "os esboços de teorização sobre o 'capitalismo periférico', ensaiados no final dos anos 70, valem apenas pelas ricas sugestões que contêm”. Em seu diário, Furtado (2019, p. 261) relatou um simbólico encontro com Prebisch em dezembro de 1978.

Ontem tive a oportunidade de ouvir Prebisch, no Centro de Estudos do Desenvolvimento da OCDE. O Centro comemorava seus quinze anos e promovia uma grande reunião. Prebisch está bem, mais gordo do que quando o vi em Washington há uns dois anos. A face mais sanguínea do que de costume. Sempre jovial, 
demostrando real satisfação em me ver. Falou em inglês, o que lhe tira grande parte do brilho. E falou de pé como nos grandes momentos, nos velhos tempos. Tratou essencialmente de política econômica, criticando o que poderíamos chamar de doutrina vulgar do desenvolvimento. $\mathrm{O}$ crescimento de produtividade, nos países subdesenvolvidos (chama-me atenção que ele fale em "developing countries"), não vai acompanhando da repartição dos frutos do progresso técnico. O mecanismo do mercado opera no sentido de concentrar a renda. Não estão presentes as mesmas forças sociais que nos países desenvolvidos fazem que os salários reais aumentem com a produtividade. Torna-se necessário, portanto, introduzir instrumentos de política compensatórios.

Logo adiante, o próprio Furtado (2019, p. 261-262) reconheceu a filiação do mestre Prebisch aos seus discípulos, ao dizer que Prebisch "defendeu essa tese (que ele aprendeu com os discípulos dele em anos recentes) com grande ênfase, espantando esse exame de velhas raposas que rondam em torno das mesas de conferência da OCDE". Por último, ressaltamos um outro excerto do mesmo encontro, no qual Furtado (2019, p. 262) destacou sua visão sobre Prebisch nos anos setenta.

Eu me perguntava se ele é hoje mais "progressista" do que foi três decênios atrás quando deu a grande briga da Cepal. Creio que não. Mas o extraordinário é que ele não seja mais conservador. Em todo caso, ele faz uma enorme inveja a muita gente da geração dele, e mesmo muito mais moça, pelo fato de que se mantém presente, continua sendo ouvido, ainda dá susto em muito funcionário do Departamento de Estado e põe em pânico muito burocrata internacional. Em todo caso, é um prazer ouvi-lo.

Finalmente, encerramos nosso trajeto com o que talvez tenha sido um dos últimos encontros entre mestre e discípulo nos anos oitenta. Nesses anos, a América Latina contraiu uma volumosa dívida externa, colocando os países em uma situação calamitosa quando o FED triplicou os juros estadunidenses, entre 1977 e 1981. O resultado imediato foi a quebra generalizada de empresas, instituições financeiras e Estados com baixa credibilidade com dívidas para negociar. Esse era mais um combate para os autores.

Entre 23 e 26 de agosto de 1983, mestre e discípulo, em posições equivalentes, estiveram lado a lado no seminário La construcción de la democracia argentina ${ }^{13}$ debatendo a redemocratização, saídas para crise da dívida, além de

\footnotetext{
${ }^{13}$ A descrição completa do seminário foi publicada em Deuda y soberanía (1984).
} 
reflexões para um novo projeto de sociedade. Em agosto do ano seguinte, Furtado, de volta com seus direitos políticos, retornou a Buenos Aires por dois dias, onde afirmou ter tido uma longa conversa com Prebisch. Furtado reencontrou Prebisch como assessor especial do governo democrático de Raúl Alfonsín, na linha de frente da renegociação do FMI. Nesse episódio, Furtado (2019, p. 295) não deixou de alfinetar o autor, revelando que ambos ainda sustentam diferentes posições.

Prebisch continua a ser um ingênuo político. $O$ que na cabeça dele é claro, considera viável na realidade. Imagina que pode obter "concessões" da direção do FMI por cima da cabeça dos funcionários mais "ortodoxos". Tratei por todos os meios de explicar-lhes que, se abrirmos as portas para o FMI, estaremos condenados a fazer concretas concessões, e eles dividirão nossas próprias forças.

Porém, o discípulo nunca deixou de admirar o mestre, quando Prebisch faleceu no dia 19 de abril de 1986, Furtado, no mês seguinte, elaborou um texto em sua homenagem (Furtado, 2011), no qual escreveu:

Seu pensamento estava sempre voltado para o mundo real, em particular aquele sobre o qual podemos agir. Não se permitia devaneios. Quando abandonou sua última função de assessoria, junto ao governo de Raúl Alfonsín, veio-lhe o sentimento de que sua vida ativa se esgotava. Não lhe interessava o papel de simples testemunha. Desejou que a morte lhe chegasse rápida, sem vacilações. Cumpriu-se o destino.

\section{Considerações finais}

Analisamos neste artigo a trajetória de dois renomados economistas que ocupam o panteão dos pioneiros do desenvolvimento, Celso Furtado e Raúl Prebisch. Como descrito, a vinculação desses autores foi forjada através da relação mestre-discípulo. Ao longo de cada um dos três momentos traçados no artigo, essa relação modificou-se ao sabor da conjuntura latino-americana, assim revelando suas diferenças teóricas, ideológicas e os distintos tons de esperança na luta pelo subdesenvolvimento. Outrossim, o artigo também trouxe à baila a pluralidade do estruturalismo latino-americano, na medida em que revelamos divergências entre o pensamento de autores que muitas vezes são tidos por iguais.

É notório que o caminho que percorremos nesse artigo expôs um mestre (Prebisch) que nos anos cinquenta construiu uma agenda de pesquisa percorrida 
por vários de seus discípulos da Cepal. O discípulo Furtado talvez tenha sido o que mais longe percorreu esse trajeto, superando o próprio mestre em diversos aspectos. Furtado muito cedo tornou-se um certo tipo de patrono do estruturalismo latino-americano, ao inserir a dimensão histórica ao método (histórico-estrutural) e, sobretudo, pela formulação de uma autêntica teoria do subdesenvolvimento. Com efeito, a "inversão dos papéis" mestre-discípulo tornou-se, de fato, patente dois decênios adiante, quando o mestre Prebisch apresentou seu Capitalismo periférico, retomando traços vitais da obra de seu discípulo Furtado.A saber, entre os principais estavam a adoção da abordagem do excedente e dos aspectos culturais para análise do desenvolvimento.

Também é digno de nota lembrar que ao apresentar o trajeto desses autores estamos confrontando a realidade latino-americana. Furtado e Prebisch estiveram no bojo de um período de grandes transformações na região, passando pela elaboração de projetos de desenvolvimento nos anos cinquenta, atravessando a esperança por reformas nos anos sessenta e, por fim, confrontando a nova dependência cristalizada nos anos setenta. Ambos sempre à frente do palco latino-americano.

\section{Referências}

BARBOSA,A. F. O anti-herói desenvolvimentista. Novos Estudos - CEBRAP. n. 94, p. 217-229, nov. 2012.

BELINI, C. El Plan Prebisch de 1955, los dilemas del desarrollo argentino y las controversias en torno a los legados económicos del peronismo. Revista de Indias. v. 78, n. 273, p. 593-629, 2018.

BIANCHI, A. M. Para auditórios diferentes, diferentes argumentos: retórica econômica nos primórdios da escola latino-americana. In: GALA, P.; REGO, J. M. (Org.). A história do pensamento econômico como teoria e retórica: ensaios sobre metodologia em economia. São Paulo: Editora 34, p. 205-230, 2003.

BIANCONI, R. Estagnação latino-americana e estratégia brasileira de desenvolvimento: análises do início do exílio de Celso Furtado. História Econômica \& História de Empresas. v. 19, n. 1, p. 155-188, 2016.

BIANCONI, R.; COUTINHO, M. C. O desenvolvimento como processo 
de mudança cultural: as conexões entre excedente e estruturas sociais na visão de Celso Furtado. Nova Economia. v. 29, n. esp., p. 1141-1169, 2019.

BIELSCHOWSKY, R. Pensamento econômico brasileiro: o ciclo ideológico do desenvolvimento. 5. ed. Rio de Janeiro: Contraponto, 2004.

BIELSCHOWSKY, R. Prebisch e Furtado. In: GURRIERI, A. (Org.). O Manifesto Latino-Americano e outros ensaios. Rio de Janeiro: Contraponto; Centro Internacional Celso Furtado de Políticas para o Desenvolvimento, p. 7-14, 2011.

BIELSCHOWSKY, R.A trajetória histórica do pensamento da Cepal: 19481998. In: BRANDÃO, C. A. (Org.). Teorias e políticas do desenvolvimento latino- americano. Rio de Janeiro: Contraponto; Centro Internacional Celso Furtado de Políticas para o Desenvolvimento, p. 47-92, 2018.

BOIANOVSKY, M. Furtado and the structuralist-monetarist debate on economic stabilization in Latin America. History of Political Economy. v. 44, n. 2, p. 1-57, 2012.

COMISSÃO ECONÔMICA PARA A AMÉRICA LATINA E O CARI$\mathrm{BE}$ (Cepal).El desequilibrio externo en el desarrollo económico latinoamericano: el caso de México. Repositório Digital da CEPAL, 15 maio 1957.Disponível em: <https://repositorio.cepal.org/handle/11362/14439>.Acesso em: 21 dez. 2020.

D'AGUIAR, R. F. Introdução. In: FURTADO, C. Ensaios sobre a Venezuela: subdesenvolvimento com abundância de divisas. Rio de Janeiro: Contraponto: Centro Internacional Celso Furtado de Políticas para o Desenvolvimento, p. 9-33, 2008.

DI FILIPPO, A. The structuralism of Prebisch and the integration of Latin America. In: FERNÁNDEZ,VICTOR RAMIRO; BRONDINO, G. (Org.). Development in Latin America: critical discussions from the periphery. London, United Kingdom: Palgrave Macmillan, p. 215-235, 2019.

DOSMAN, E. J. Raúl Prebisch (1901-1986): a construção da América Latina 
e do terceiro mundo. Rio de Janeiro: Contraponto: Centro Internacional Celso Furtado de Políticas para o Desenvolvimento, 2011.

EL CID EDITOR. Deuda y soberanía. Buenos Aires,Argentina: El Cid Editor/ Fundación para la Democracia en la Argentina, 1984.

FONSECA, P. C. D.; SALOMÃO, I. C. Furtado vs. Prebisch: Latin American controversy. Investigación Económica. v. 77, n. 306, p. 74-93, 2018.

FURTADO, C. M. [Carta] s.d., Cambridge [para] BOTI, R. Santiago de Chile. Descreve sua chegada à Inglaterra.Acervo pessoal do Centro Internacional Celso Furtado.

FURTADO, C. M. Características gerais da economia brasileira. Revista Brasileira de Economia. v. 4, n. 1, p. 7-37, 1950.

FURTADO, C. M. A economia brasileira: contribuição à análise do seu desenvolvimento. Rio de Janeiro: Ed. A Noite, 1954.

FURTADO, C.M. (1959). Formação econômica do Brasil. São Paulo: Companhia das Letras, 2007.

FURTADO, C. M. (1961). Desenvolvimento e subdesenvolvimento. Rio de Janeiro: Contraponto; Centro Internacional Celso Furtado de Políticas para o Desenvolvimento, 2009.

FURTADO, C. M. Dialética do desenvolvimento. Rio de Janeiro: Fundo da Cultura, 1964.

FURTADO, C. M. Subdesenvolvimento e estagnação na América Latina. Rio de Janeiro: Editora Civilização Brasileira, 1966.

FURTADO, C. M. (1974). O mito do desenvolvimento econômico. São Paulo: Círculo do Livro, 1985.

FURTADO, C. M. Prefácio a Nova Economia Política. 3. ed. Rio de Janeiro: Paz e Terra, 1977. 
FURTADO, C. M. Pequena introdução ao desenvolvimento: enfoque interdisciplinar. 1. ed. São Paulo: Editora Nacional, 1980.

FURTADO, C. M. Raúl Prebisch, el gran heresiarca. Revista Comercio Exterior. v. 37, n. 5, p. 374-382, maio 1987.

FURTADO, C. M. Brasil: a construção interrompida. Rio de Janeiro: Paz e Terra, 1992.

FURTADO, C. M. Em busca de novo modelo: reflexões sobre a crise contemporânea. São Paulo: Paz e Terra, 2002.

FURTADO, C. M. Sobre Raul Prebisch. Cadernos do Desenvolvimento. v. 6, n. 9, p. 442-444, dez. 2011.

FURTADO, C. M. Obra autobiográfica. 1. ed. São Paulo: Companhia das Letras, 2014.

FURTADO, C. M. Diários intermitentes: 1937-2002. 1. ed. São Paulo: Companhia das Letras, 2019.

GAUHAR, A.; PREBISCH, R. Raul Prebisch. Third World Quarterly. v. 2, n. 1, p. 14-20, jan. 1980.

HIRSCHMAN, A. O. ideologias do desenvolvimento econômico na América Latina. In: HIRSCHMAN, A. O. (Org.). Monetarismo vs. estruturalismo: um estudo sobre a América Latina. Coleção Societas. 1. ed. Rio de Janeiro: Lidador, p. 9-49, 1967.

HODARA, J. Prebisch y la Cepal: sustancia, trayectoria y contexto institucional. 1. ed. México: El Colegio de México, 1987.

HODARA, J. Prebisch y Urquidi: vidas paralelas. Araucaria - Revista Iberoamericana de Filosofía, Política y Humanidades, n. 19, p. 45-63, 2008.

IGLESIAS, E.V. Raúl Prebisch y David Pollock: la causa del desarrollo. In: INTAL (Org.). Raúl Prebisch: el poder, los principios y la ética del desarrollo. 1. ed. Buenos Aires: BID-INTAL, p. 5-9, 2006. 
JAURETCHE, A. El Plan Prebisch: retorno al coloniaje. 3. ed. Buenos Aires: Arturo Peña Lillo, 1973.

LOVE, J. Furtado e o estruturalismo. In:BRESSER-PEREIRA, L. C.; REGO, J. M. (Org.). A grande esperança em Celso Furtado: ensaios em homenagem aos seus 80 anos. São Paulo: Editora 34, p. 221-252, 2001.

MAGARIÑOS, M. Diálogos con Raúl Prebisch.1.ed. México:BANCOMEXT; Fondo de Cultura Económica, 1991.

MALLORQUÍN, C. Aventuras y desventuras de un economista brasileño (circa 1964-1976). In: Prebisch y Furtado: el estructuralismo latinoamericano. 1. ed. México: Benemérita Universidad Autónoma de Puebla, p. 33-135, 1999.

MARTÍN, J.J. M. La sociología del desarrollo en América Latina: una tensión permanente entre democracia y crecimiento económico. Espacio Abierto: Cuaderno Venezolano de Sociología. v. 25, n. 3, p. 171-181, set. 2016.

MEDEIROS, F. J. M.; COSENTINO, D. DO V. Celso Furtado e Raúl Prebisch frente à crise do desenvolvimentismo da década de 1960. Revista de Economia (Curitiba).v. 41, n. 74, p. 150-179, 2020.

PREBISCH, R. (1949). O desenvolvimento econômico da América Latina e alguns de seus principais problemas. In: GURRIERI, A. (Org.). O Manifesto Latino-Americano e Outros Ensaios. Rio de Janeiro: Contraponto; Centro Internacional Celso Furtado de Políticas para o Desenvolvimento, p. 95-151, 2011a.

PREBISCH, R. El estudio económico de América Latina 1949. Chile: Cepal, 1950.

PREBISCH, R. (1951). Problemas teóricos e práticos do desenvolvimento econômico. In: GURRIERI,A. (Org.). O Manifesto Latino-Americano e outros ensaios. Rio de Janeiro: Contraponto; Centro Internacional Celso Furtado de Políticas para o Desenvolvimento, p. 247-297, 2011c.

PREBISCH, R. (1954). La cooperación internacional en la política de de- 
sarrollo latinoamericano. In: GURRIERI, A. (Org.). La obra de Prebisch en la Cepal, v. 1. México: Fondo de Cultura Económica, p. 298-393, 1982.

PREBISCH, R. Informe preliminar acerca de la situación económica. Argentina, Buenos Aires: Presidencia de la Nación, 1955.

PREBISCH, R. (1961). O falso dilema entre desenvolvimento econômico e estabilidade monetária. In: PREBISCH, R. (Org.). O Manifesto Latino- Americano e outros ensaios. Rio de Janeiro: Contraponto; Centro Internacional Celso Furtado de Políticas para o Desenvolvimento, p. 393-456, 2011 b.

PREBISCH, R. (1963). Dinâmica do desenvolvimento latino-americano. 2. ed. Rio de Janeiro: Fundo da Cultura, 1968.

PREBISCH, R. Crítica al capitalismo periférico. Revista de la Cepal, n. 1, p. 7-73, 1976.

PREBISCH, R. Estructura socioeconómica y crisis del sistema: reflexiones al cumplirse nuestros primeros treinta años. Revista de la Cepal. n. 6, p. 167264, 1978.

PREBISCH, R. (1981). Capitalismo periférico: crisis y transformación. 1. ed. (reimpressão). México: Fondo de Cultura Económica, 1984.

PREBISCH, R. (1980). Hacia una teoría de la transformación. Revista de la Cepal. n. 96, p. 27-71, dez. 2008.

PREBISCH, R. Cinco etapas de mi pensamiento sobre el desarrollo. El Trimestre Económico. v. I (2), n. 198, p. 1077-1096, jun. 1983.

RODRÍGUEZ, O. O estruturalismo latino-americano. Rio de Janeiro: Civilização Brasileira, 2009.

SCHATAN, J. Raúl Prebisch, maestro y guía. Investigación Económica. v. 45, n. 177 , p. 303-313, set. 1986.

SOUZA, L. E. S. Antecedentes desenvolvimentistas na formação intelectual 
de Raúl Prebisch. Revista de Economia Política e História Econômica. n. 33, p. 5-17, jan. 2015.

SUNKEL, O. La inflación chilena: un enfoque heterodoxo. El Trimestre Económico. n. 25(4), dez. 1958.

TOYE, J.; TOYE, R. Raúl Prebisch y los Límites de la Industrialización. In: INSTITUTO PARA LA INTEGRACIÓN DE AMÉRICA LATINA (INTAL) (Org.). Raúl Prebisch: el poder, los principios y la ética del desarrollo. 1. ed. Buenos Aires: BID-INTAL, p. 23-32, 2006.

VÁSQUEZ, N. Inflación y desarrollo en Chile y México. Panorama Económico. n. 170, jul. 1957.

VIEIRA, R. M. Entrevista com Celso Furtado. História Oral. v. 7, p. 21-40, jun. 2004. 